\title{
Fuzzy Inference System to Predict HE Performance
}

\author{
I. N. Sutapa, Z. J. H. Tarigan, J. Mochtar, and J. Rahardjo
}

\begin{abstract}
The article discusses a methods to predict Higher Education (HE) performance based on four perspectives of Balanced Scorecards. The relationship model among perspectives to the performance was developed using fuzzy inference system. There are 12 predictors variable are developed as Key Performance Indicator's of BSC. The expert were chosen from qualified national assessor to evaluate the membership function of the predictive variable, and to develop the inference rules from predictor variable to output variable. Based on confirmation and validation model design to the expert, the model can be used to predict the HE's performance.
\end{abstract}

Index Terms-Fuzzy inference system, balanced scorecards, higher education performance.

\section{INTRODUCTION}

On a tight competition of HE, it needs to develop a well planned actions to win the competition. One of the input needed to create action plan is understanding the future performance of the system. To understand it, HE needs a performance measurement tools which can be used to predict the future performance. There are various methods to predict the performance of the system, one of the methods is expert judgements [1]. Knowledge and experience of the expert can help HE to establish key performance measures that have a significant impact on their performance. Expert judgment also can help HE to evaluate the influence relationship among key performance measurements, and finally to predict future performance [2]. On the other hand, in reality most information and expert knowledge are not expressed in exact data, but in subjective qualitative data [3].

This article discusses HE performance predictions using experience and expert knowledge. The expert was choosen from experienced education managers and qualified education assessors. Based on their experience in managing education and assessing various aspects of education. Furthermore, we translate their expertise in determining key performance measures into variables and fuzzy sets. Then, translate the relationship of influence between measurements in shaping the overall HE performance, using a fuzzy inference system. The resulting model is used to control and predict the performance of $\mathrm{HE}$ in the future.

\section{BALANCED SCORECARD AND THE MEASUREMENT}

Manuscript received February 13, 2019; revised April 1, 2019

I. N. Sutapa and J. Rahardjo are with Industrial Engineering Department, Petra Christian University, Surabaya 60236, Indonesia (e-mail: mantapa@petra.ac.id, jani@petra.ac.id).

Z. J. H. Tarigan is with Management Department, Petra Christian University, Surabaya 60236, Indonesia (e-mail: zeplin@ petra.ac.id).

J. Mochtar was with Quality Assurance Institute and she is with English Department, Petra Christian University, Surabaya 60236, Indonesia (e-mail: jennymd@petra.ac.id).

\section{A. Balanced Scorecards}

Balanced Scorecard (BSC) is a tool to structure measures from four perspectives, giving a top management a comprehensive view of the business, short-term and long-term, financial and non-financial, as well as current and future to formulate vision and strategy. Its focus is on how to link the measures with strategic activities from finance, customer, internal business process and learning and growth perspectives [4]. It is asumed that there is a causal relationship between the four perspectives in translating the company's vision and strategy into action.

\section{B. Measurement Framework}

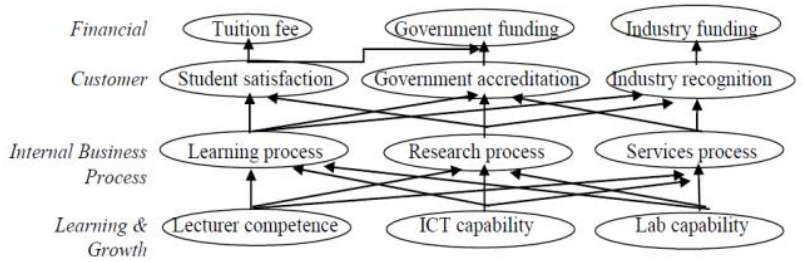

Fig. 1. HE's strategic map

In order to translate vision and strategy, objectives and targets are set and the measures and initiatives are designed and aligned by the nominal group techniques. Herein, the designed measures and aligned initiatives interrelate each other in a relation called horizontal linkage. In this paper, we attempt to present a suggestion of a measurement system based on BSC with introducing fuzzy inference [5], [6]. The relations among measures of each perspective consist of as the followings. In order to improve internal process continuously, $\mathrm{HE}$ are required to maintenance and improve the learning and growth of human resources and infrastucture. For doing this, HE need to measure lecturers competence, ICT and laboratory capability. The inisiatives to improve lecturers competence are training and expereiencing of teaching, researching, and industry services. To improve ICT and Lab capability, HE need to adopt the latest hard and soft technology. The measurement for internal business process to improve student, society, and goverment satisfaction are improvement for learning process, research, and industry services processes. To do these, the inisiatives of HE i.e. update curricullum follow the market and science and technology development, monitoring and evaluating learning process, research, industry services regularly, and develop collaboration with reputation university and industry to do teaching, research and consulting services. To support HE's financial, customer perspective i.e. student, society, and goverment's satisfaction must be improved. The initiatives of these measurement are control and monitoring the student saisfaction index, HE accreditation by goverment, and industry recognition. Finally, the measures for financial perspective are student tuition fee, government 
funding/grants, and industry funding/grant. The initiatives are increase the size of student, increase the research quality, and improve consultancy services and number of patents for the industry. The following (Fig. 1) presents the BSC strategy map constructed from the causal relationship of all measures.

\section{FUZZY INFERENCE SYSTEM TO PREDICT HE’S PERFORMANCE}

Fuzzy inference system (FIS) is the actual process of mapping from a given input to an output using fuzzy logic. In this research, the inputs are measurement of each BSC perspective and the output is HE's performance. In terms of the inference process, there are two main types of FIS, i.e. the Mamdani type [7] and the Sugeno type [8]. In this research, we used Mamdani fuzzy methods as a FIS, this methods is more widely used mostly because of the reasonable results with a relatively simple structure it provides, and the intuitive interpretable nature of the rule base [9], [10]. There are 6 steps for Mamdani FIS model: 1) Determining a set of fuzzy IF-THEN rules, 2) Fuzzifying the inputs using the input membership functions, 3) Combining the fuzzified inputs according to the fuzzy rules to establish a rule strength (Fuzzy Operations), 4) Finding the consequence of the rule by combining the rule strength and the output membership function (implication), 5) Combining the consequences to get an output distribution (aggregation), and 6) Defuzzifying the output distribution (this step is only if a crisp output (class) is needed).

\section{A. Membership Functions}

Each of BSC perspective measurement is defined as a fuzzy variable, and its value is defined as "Low", "Medium", and "High" fuzzy set. Membership function for each fuzzy set was formulated by four experts. Following are the membership function of "Low", "Medium", and "High" fuzzy set for each measurement after normalized on $[0,1]$ interval. For HE's performance is used 5 fuzzy sets, i.e.
"Very Low”, “Low”, "Medium”, "High”, "Very High” fuzzy set, with membership function also formulated by four assessors as expert. Each membership function for "Low" and "High" is approximated by trapezoidal function $(t z(\because,, ;))$ and "Medium" fuzzy set is approximated by triangular function $(\operatorname{ta}(\because, \cdot))$.

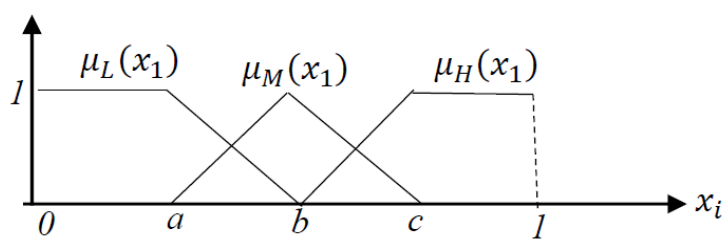

Fig. 2. Membership function of fuzzy set "low", "medium", and "high".

where membership function for "Low", "Medium", and "High" are formulated by

$$
\begin{gathered}
\mu_{L}\left(x_{i}\right)=t z(0,0, a, b)=\left\{\begin{array}{ll}
1 & 0 \leq x_{i}<a \\
\frac{b-x_{i}}{b-a} & a \leq x_{i}<b
\end{array} \text { and } \mu_{H}\left(x_{i}\right)=\right. \\
t z(b, c, 1,1)= \begin{cases}\frac{x_{-}-b}{c-b} & b \leq x_{i}<c \\
1 & c \leq x_{i} \leq 1\end{cases} \\
\mu_{M}\left(x_{i}\right)=t a(a, b, c)= \begin{cases}\frac{x_{i-a}}{b-a} & a \leq x_{i}<b \\
\frac{c-x_{i}}{c-a} & b \leq x_{i}<c\end{cases}
\end{gathered}
$$

Table I presents the "Low", "Medium", and "High" fuzzy membership functions for 12 fuzzy variables to measure four BSC perspectives, as well as the fuzzy membership function set for HE's performance. The determination of the values of $a, b$, and $c$ of each fuzzy membership function for each fuzzy variable is determined from the average fuzzy membership based on the opinion of all experts. In the Table IV, the values $a, b$, and $c$ are displayed after normalization in the interval [0,

\begin{tabular}{|c|c|c|c|c|c|}
\hline \multirow{2}{*}{\multicolumn{2}{|c|}{ Fuzzy Variable }} & \multicolumn{4}{|c|}{ Membership Function of Fuzzy Set } \\
\hline & & Low & $\mathrm{Med}$ & & High \\
\hline \multicolumn{2}{|c|}{ Lecturer competent $\left(X_{l}\right)$} & $t z(0,0, .5, .7)$ & $\mu_{M}\left(x_{1}\right)=\operatorname{ta}($ & $\mu_{H}($ & $=t z(.7, .9,1,1)$ \\
\hline \multicolumn{2}{|c|}{ ICT capability $\left(X_{2}\right)$} & $t z(0,0, .4, .6)$ & $\mu_{M}\left(x_{2}\right)=\operatorname{ta}($ & $\mu_{H}$ & $=\operatorname{tz}(.6, .8,1,1)$ \\
\hline \multicolumn{2}{|c|}{ Lab capability $\left(X_{3}\right)$} & $t z(0,0, .3, .5)$ & $\mu_{M}\left(x_{3}\right)=\operatorname{ta}($ & $\mu_{H}$ & $=\operatorname{tz}(.5, .7,1,1)$ \\
\hline \multicolumn{2}{|c|}{ Learning process $\left(X_{4}\right)$} & $t z(0,0, .4, .6)$ & $\mu_{M}\left(x_{4}\right)=\operatorname{ta}($. & $\mu_{H}$ & $=t z(.6, .8,1,1)$ \\
\hline \multicolumn{2}{|c|}{ Research process $\left(X_{5}\right)$} & $t z(0,0, .4, .6)$ & $\mu_{M}\left(x_{5}\right)=\operatorname{ta}($. & $\mu_{H}$ & $=\operatorname{tz}(.6, .8,1,1)$ \\
\hline \multicolumn{2}{|c|}{ Services process $\left(X_{6}\right)$} & $t z(0,0, .3, .6)$ & $\mu_{M}\left(x_{6}\right)=\operatorname{ta}($. & $\mu_{H}$ & $=\operatorname{tz}(.6, .9,1,1)$ \\
\hline \multicolumn{2}{|c|}{ Student satisfaction $\left(X_{7}\right)$} & $=t z(0,0, .5, .7)$ & $\mu_{M}\left(x_{7}\right)=\operatorname{ta}($. & $\mu_{H}$ & $=\operatorname{tz}(.7, .9,1,1)$ \\
\hline \multicolumn{2}{|c|}{ Gov. accreditation $\left(X_{8}\right)$} & $=t z(0,0, .4, .6)$ & $\mu_{M}\left(x_{8}\right)=\operatorname{ta}($. & $\mu_{H}$ & $=\operatorname{tz}(.6, .8,1,1)$ \\
\hline \multicolumn{2}{|c|}{ Industry recognition $\left(X_{9}\right)$} & $=t z(0,0, .3, .5)$ & $\mu_{M}\left(x_{9}\right)=\operatorname{ta}($. & $\mu_{H}$ & $=t z(.5, .7,1,1)$ \\
\hline \multicolumn{2}{|c|}{ Student tuition fee $\left(X_{10}\right)$} & $=t z(0,0, .5, .7)$ & $\mu_{M}\left(x_{10}\right)=\operatorname{ta}($ & $\mu_{H}($ & $=t z(.7, .9,1,1)$ \\
\hline \multicolumn{2}{|c|}{ Gov. funding $\left(X_{11}\right)$} & $=t z(0,0, .4, .6)$ & $\mu_{M}\left(x_{11}\right)=\operatorname{ta}($ & $\mu_{H}($ & $=t z(.6, .8,1,1)$ \\
\hline \multicolumn{2}{|c|}{ Industry funding $\left(X_{12}\right)$} & $=t z(0,0, .3, .5)$ & $\mu_{M}\left(x_{12}\right)=t a($ & $\mu_{H}($ & $=t z(.5, .7,1,1)$ \\
\hline \multirow{2}{*}{$\begin{array}{l}\text { HE's } \\
\text { Perfor-mance }(Y)\end{array}$} & Very Low & Low & Medium & High & Very High \\
\hline & $\mu_{V L}(y)=t z(0,0, .1, .3)$ & $\begin{array}{l}\mu_{L}(y) \\
=\operatorname{ta}(.1, .3, .5)\end{array}$ & $\begin{array}{l}\mu_{M}(y) \\
=\operatorname{ta}(.3, .5, .7)\end{array}$ & $\begin{array}{l}\mu_{H}(y) \\
=\operatorname{ta}(.5, .7, .9)\end{array}$ & $\begin{array}{l}\mu_{V H}(y) \\
=t z(.7, .9,1,1)\end{array}$ \\
\hline
\end{tabular}
$1]$.

TABLE I: MEMBERSHIP FunCTION FOR FuZZY SET LOw, MEDIUM, AND HigH (NoRMALIZED)

\begin{tabular}{|c|c|}
\hline Rules & Inference \\
\hline$R_{1}$ & IF $x_{1}$ is $\mu_{L}\left(x_{1}\right)$ AND $x_{4}$ is $\mu_{L}\left(x_{4}\right)$ AND $x_{7}$ is $\mu_{L}\left(x_{7}\right)$ AND $x_{10}$ is $\mu_{L}\left(x_{10}\right)$ THEN $y$ is $\mu_{V L}(y)$ \\
\hline$R_{2}$ & IF $x_{1}$ is $\mu_{L}\left(x_{1}\right)$ AND $x_{4}$ is $\mu_{L}\left(x_{4}\right)$ AND $x_{7}$ is $\mu_{L}\left(x_{7}\right)$ AND $x_{10}$ is $\mu_{M}\left(x_{10}\right)$ THEN yis $\mu_{V L}(y)$ \\
\hline$\vdots$ & $\begin{array}{l}-1 \\
\end{array}$ \\
\hline$R_{5}$ & IF $x_{1}$ is $\mu_{M}\left(x_{1}\right) A N D x_{4}$ is $\mu_{L}\left(x_{4}\right)$ AND $x_{7}$ is $\mu_{L}\left(x_{7}\right)$ AND $x_{10}$ is $\mu_{L}\left(x_{10}\right)$ THEN $y$ is $\mu_{V L}(y)$ \\
\hline$R_{6}$ & IF $x_{1}$ is $\mu_{M}\left(x_{1}\right) A N D x_{4}$ is $\mu_{M}\left(x_{4}\right) A N D x_{7}$ is $\mu_{L}\left(x_{7}\right)$ AND $x_{10}$ is $\mu_{L}\left(x_{10}\right)$ THEN yis $\mu_{L}(y)$ \\
\hline$R_{7}$ & IF $x_{1}$ is $\mu_{M}\left(x_{1}\right)$ AND $x_{4}$ is $\mu_{L}\left(x_{4}\right)$ AND $x_{7}$ is $\mu_{M}\left(x_{7}\right)$ AND $x_{10}$ is $\mu_{L}\left(x_{10}\right)$ THEN yis $\mu_{L}(y)$ \\
\hline$\vdots$ & 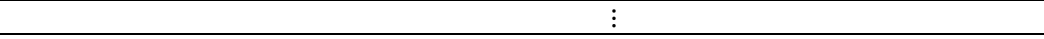 \\
\hline
\end{tabular}

TABLE II: FUZZY INFERENCES 


\begin{tabular}{cc}
\hline$\vdots$ & $\vdots$ \\
\hline$R_{19}$ & IF $x_{1}$ is $\mu_{M}\left(x_{1}\right)$ AND $x_{4}$ is $\mu_{M}\left(x_{4}\right)$ AND $x_{7}$ is $\mu_{M}\left(x_{7}\right)$ AND $x_{10}$ is $\mu_{H}\left(x_{10}\right)$ THEN yis $\mu_{M}(y)$ \\
\hline$R_{20}$ & IF $x_{1}$ is $\mu_{H}\left(x_{1}\right)$ AND $x_{4}$ is $\mu_{H}\left(x_{4}\right)$ AND $x_{7}$ is $\mu_{M}\left(x_{7}\right)$ AND $x_{10}$ is $\mu_{M}\left(x_{10}\right)$ THEN yis $\mu_{H}(y)$ \\
\hline$\vdots$ & $\vdots$ \\
\hline$R_{45}$ & IF $x_{1}$ is $\mu_{H}\left(x_{1}\right)$ AND $x_{4}$ is $\mu_{H}\left(x_{4}\right)$ AND $x_{7}$ is $\mu_{H}\left(x_{7}\right)$ AND $x_{10}$ is $\mu_{H}\left(x_{10}\right)$ THEN yis $\mu_{V H}(y)$ \\
\hline$\vdots$ & $\vdots$ \\
\hline$R_{1080}$ & IF $x_{3}$ is $\mu_{H}\left(x_{3}\right)$ AND $x_{6}$ is $\mu_{H}\left(x_{6}\right)$ AND $x_{9}$ is $\mu_{H}\left(x_{9}\right)$ AND $x_{12}$ is $\mu_{H}\left(x_{12}\right)$ THEN is $\mu_{V H}(y)$ \\
\hline
\end{tabular}

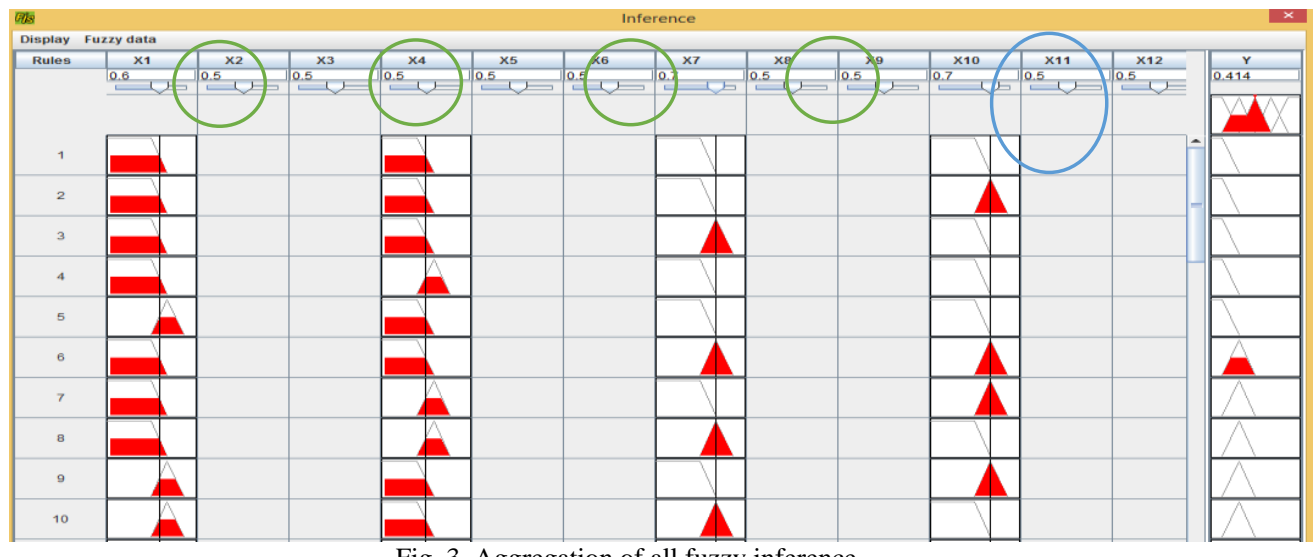

Fig. 3. Aggregation of all fuzzy inference.

\section{B. Fuzzy Rules and Fuzzy Inference System}

Fuzzy rules are core of the fuzzy inference system. Fuzzy inference rules for performance measurement are based on the knowledge and experience of the expert or assessor. We used If-Then type fuzzy rules to converts the fuzzy input to the fuzzy output. From HE's strategic map (Fig. 1) we derived 1080 rules (presented at Table II), resulted from 24 paths of measurement of learning and growth perspective until financial perspective and finally to the HE's performance, where each path has 45 rules.

In this fuzzy inference, we used MAX-MIN composition to transform inputs fuzzy to output fuzzy. Aggregation of all fuzzy rules using MIN operator, was obtained a combined fuzzy set with minimal value, which is a combination of all fuzzy sets, results of fuzzy reasoning from each fuzzy rule. Below (Fig. 3) is the result of a part of aggregation of fuzzy inference, that is calculation result of one reasoning path (45 rules), from variable fuzzy $x_{1}$ lecturer competence, $x_{4}$ learning process, $x_{7}$ student satisfaction, and $x_{10}$ student suition fee. For example, IF the lecturer competence is Low (crisp value is 0.6) AND learning process is Low (0.5) AND student satisfaction is Medium (0.7) AND tution fee is Medium (0.7) THEN HE's performance is approaching Medium (crisp value is 0.414 ).

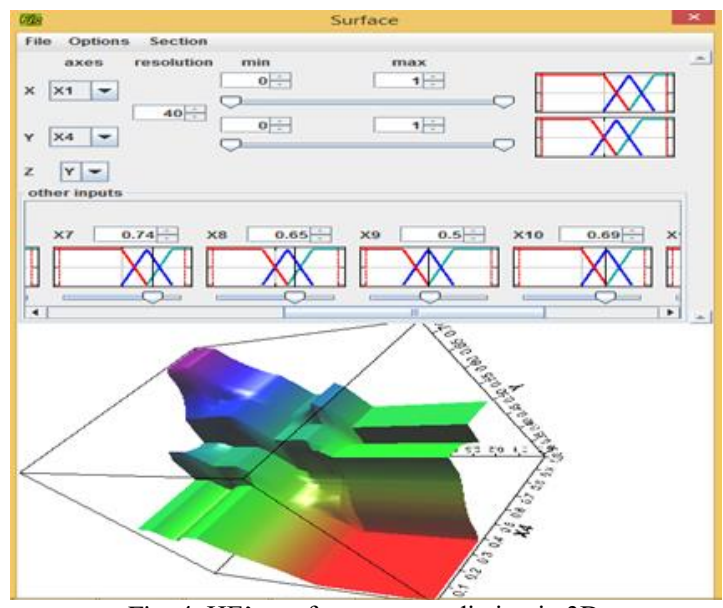

Fig. 4. HE's performance prediction in 3D.
HE's performance predictions can be observed from 3D visualizations, such as Fig. 4. If student satisfaction $x_{7}$ and student tuition fee $x_{10}$ are retained in medium positions, then the impact of lecturer competence $x_{1}$ and learning process $x_{4}$ on HE's performance can be predicted, in the following visual example, increasing on the lecturer competence $x_{l}$ and learning process $x_{4}$ has effect on increasing of HE's performance. The same observation can also be done on the other variables easily, just replace which variables will be observed and which are retained fixed. Similarly, if we want to observe changes in HE's performance by one predictor variable, by holding three other predictor variables, we can observe in 2D visualization, as seen in Fig. 5.

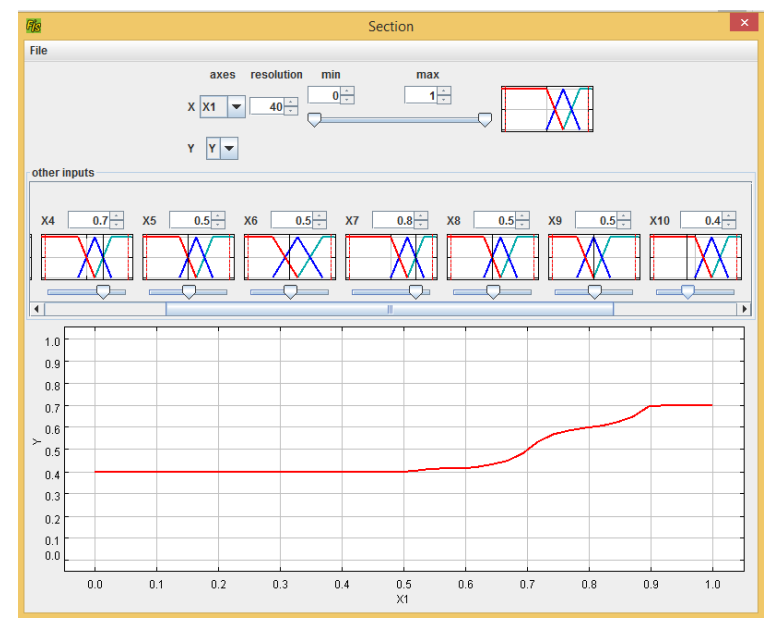

Fig. 5. HE's performance prediction in 2D

Based on confirmation and validation with the leadership of an HE, this model can predict well the performance of HE.

\section{CONCLUSION}

Fuzzy inference system that has been developed, able to predict $\mathrm{HE}$ performance based on value changes on the measurement of $4 \mathrm{BSC}$ perspectives. When detected a decrease in HE performance, it can be done early anticipation to make improvements. The measurement value used as input 
in this study, can be a qualitative assessment expressed in words, do not have to wait for reports in quantitative data. This system can also be used as a monitoring tool for HE performance, if there are changes in measurement values in some perspectives. This study has limitations, including not considering the weight of each rule and the existence of the path of two-way influence between BSC perspectives. This limitation can be an opportunity for future research. And to be more comprehensive, it can be combined with quantitative measurements.

\section{REFERENCES}

[1] Q.-L. Lin, H.-C. Liu, and D.-J. Wang, Expert Systems with Applications, vol. 40, p. 1917.

[2] L. E. Vafaei and M. Sah, Procedia Computer Science, vol. 120, p 221, 2017.

[3] F. Bobillo, M. Delgado, and J. Gomez-Romero, Expert Systems with Applications, vol. 36, p. 423, 2009.

[4] R. S. Kaplan, "Conceptual foundation of the balanced scorecard," Working Paper, 2010.

[5] T. Matsuo, "A new perspective of Mgmt," Accout Inst. of Bus. Research, Daito Bunka, 2006.

[6] M. Hakimollah et al., Int. J. of Automotive Eng., vol. 2, p. 4, 2012.

[7] E. H. Mamdani and S. Assilian, Inter. J. of Man-Mach. Stud., vol. 7, p. $1,1975$.

[8] T. Takagi and M. Sugeno, IEEE Trans. on Syst. Man and Cybern., vol. $15, \mathrm{p} 116,1985$.

[9] J. J. Jassbi et al., World Automation Congress, p. 1, 2006.

[10] R .Fahmy et al., Inter. J. of Comp. Appl. (0975 - 8887), vol. 109, no. 13, p. 6,2015 .

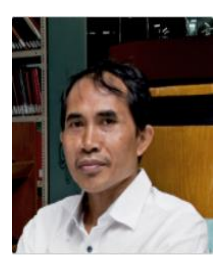

I. N. Sutapa was born in Bali, Indonesia in 1968. He graduated from Industrial Mathematics of Universitaet Kaiserslautern, Germany and doctorate of Operation Management from Brawijaya University, Malang, Indonesia. $\mathrm{He}$ is a full-time lecturer in the Industrial Engineering Department, Petra Christian University Surabaya Indonesia since 1993. The courses he teaches range from Calculus, Operational Research, Lean Manufacturing, Quality Management System, and Performance
Management. His research interest is the Mathematical model for inventory, supply chain, and decision making, performance measurement system, and quality improvement.

Z. J. H. Tarigan is a full lecturer in Graduate Program of Management at Petra Christian University, Surabaya, Indonesia, since 2006. He graduated from Management Technology of Institut Technology Sepuluh Nopember Surabaya, Indonesia, and a doctorate of Management Science from Brawijaya University, Malang, Indonesia. Previously, he worked as a Production Planning and Inventory Control manager in several major companies in Indonesia. He is also a consultant for production and inventory planning, ERP, and quality management system. The courses he teaches range from production and operation management, project management, management information system, and enterprise resources planning. His research interest in enterprise resources planning and performance management.

J. Mochtar is a full-time lecturer in the English Department of Petra Christian University, Indonesia since 1985. She obtained her MA in Literature from Arizona State University and her Doctorate, also in Literature, from the University of Indonesia. The courses she teaches range from culture to literature: Public Speaking, British Studies, Australian Studies, Drama, Popular Literature, Literature and Gender. Her research interest lies in Indonesian popular literature, popular culture and gender studies and she has published and presented papers in these areas in journals and in national and international conferences.

J. Rahardjo was born in Surabaya, Indonesia in 1962. Graduated form Management Technology of Asian Institute of Technology, Bangkok Thailand and a doctorate of Advanced Manufacturing Technology from Universiti Teknologi Melaka, Malaysia. He is a full-time lecturer in the Industrial Engineering Department, Petra Christian University Surabaya, Indonesia since 1989. The courses he teaches range from Statistical Methods, Statistical Quality Control, Quality Management System, Six Sigma, Decision Analysis, and Management Technology. His research interest lies in decision making using AHP, quality process improvement, processes design, and innovation process, and advanced manufacturing technology for SME. He also serves as a consultant of process innovation and improvement, quality management system, and six sigma for some companies in Indonesia. 